\title{
HUBUNGAN SUMBER INFORMASI DENGAN PEMBERIAN IMUNISASI TT PADA IBU HAMIL
}

\author{
Choralina Eliagita $^{1}$, Mika Oktarina ${ }^{2}$, Nuril Absari ${ }^{3}$, Ira Yunita ${ }^{4}$ \\ Sarjana Terapan Kebidanan ${ }^{1234}$ \\ STIKES Tri Mandiri Sakti Bengkulu \\ choralinaeliagita08@gmail.com
}

\begin{abstract}
The low coverage of TT immunization in pregnant women. Lack of information sources is one of the causes of low TT immunization in pregnant women. This study aims to determine the relationship of information sources with the provision of TT immunization to pregnant women in the third trimester in the working area of Karang Dapo Health Center, Musi Rawas Utara Regency. The design of this research is an analytic survey with a cross sectional approach. The sample of this study was all multiparous pregnant women TM III at the Karang Dapo Health Center, Musi Rawas Utara Regency, July 3 to July 17, 2020, as many as 31 people were taken by total sampling. Collecting data using primary data, and using a questionnaire as a research tool. The results showed that there was a relationship between the source of information and the provision of TT immunization to pregnant women in the Karang Dapo Public Health Center, Musi Rawas Utara Regency with $p$ value $=0.001$, 0.005. It is hoped that the puskesmas can become a means of adding information and carrying out active health counseling activities related to the immunization program, especially the provision of TT immunization so that it becomes a priority in the work program of the health center in providing TT immunization.
\end{abstract}

\section{Keywords $\quad$ : TT Immunization, Source of Information}

\begin{abstract}
ABSTRAK
Rendahnya cakupan imunisasi TT pada ibu hamil. Sumber informasi yang kurang merupakan salah satu penyebab rendahnya imunisasi TT pada ibu hamil. Penelitian ini bertujuan untuk mengetahui hubungan sumber informasi dengan pemberian imunisasi TT pada Ibu Hamil Trimester III di Wilayah Kerja Puskesmas Karang Dapo Kabupaten Musi Rawas Utara. Desain penelitian ini adalah survey analitik dengan pendekatan cross setional. Sample penelitian ini adalah keseluruhan ibu hamil multipara TM III di Puskesmas Karang Dapo Kabupaten Musi Rawas Utara 03 Juli-17 Juli tahun 2020 sebanyak 31 orang yang diambil secara total sampling.. Pengumpulan data menggunakan data primer, serta menggunakan kuisioner sebagai alat bantu penelitian. Hasil penelitian ada hubungan antara sumber informasi dengan pemberian imunisasi TT pada ibu hamil di Wilayah Kerja Puskesmas Karang Dapo Kabupaten Musi Rawas Utara dengan nilai $\mathrm{p}=0,001$, 0,005. Diharapkan puskesmas dapat menjadika sarana penambahan informasi dan melakukan kegiatan aktif penyuluhan kesehatan yang berhubungan dengan program imunisasi khususnya pemberian imunisasi TT sehingga menjadi prioritas dalam program kerja pihak peskesmas dalam pemberian imunisasi TT.
\end{abstract}

Kata Kunci $\quad$ : Pemberian Imunisasi TT, Sumber Informasi

\section{PENDAHULUAN}

\section{World Health Organization (WHO)} tahun 2019 angka kejadian tetanus neonatorum mengalami penurunan pada tahun 2019 sebanyak 59 ribu kasus dari 790 ribu kematian bayi, hal ini mengalami penurunan dari tahun 200 ribu kasus dari
2000 kematian bayi (Indarto, 2019).Berdasarkan data dari Kemenkes RI Angka Kematian Ibu (AKI) pada tahun 2019 sebesar 305 per 100.0000 KH. Dari 14.640 total kematian ibu yang dilaporkan hanya 4.999 , berarti ada 9.641 yang tidak dilaporkan ke pusat. Dari data tersebut, ada 83.447 keratin ibu di desa maupun 
kelurahan, sementara di Puskesmas ada 9.825 kematian ibu, dan 2.868 kematian ibu di rumah sakit Penyebab kematian ibu antara lain perdarahan (30,3\%), hipertensi $(27,1 \%)$, infeksi $(7,3 \%)$, Persalinan lama $(1,8 \%)$, abortus $(1,6 \%)$. Infeksi merupakan penyebab kedua kematian ibu, salah satu penyebab infeksi yaitu tidak mendapatkan Imunisasi TT pada saat kehamilan. (Kemenkes, 2020).

Pemberian imunisasi TT pada ibu hamil sebanyak $2 \mathrm{x}$ vaksinasi Tetanus Toksoid dengan interval pemberian 4 minggu, Imunisasi TT sangat penting karena dapat mencegah terjadinya infeksi tetanus pada ibu dan bayi saat melahirkan terutama pada ibu yang ditolong oleh tenaga non nakes, infeksi dapat terjadi akibat alat yang digunakan tidak steril (Maryunani, 2016).

Faktor risiko untuk terjadinya Tetanus Neonatorum salah satunya adalah akibat pemberian imunisasi Tetanus Toksoid pada ibu hamil yang tidak dilakukan karena dianggap tidak perlu, tidak lengkap, atau tidak sesuai dengan ketetapan program serta kurangnya informasi yang diterima dan sikap ibu hamil (Emilda, 2016). Menurut Munawaroh (2016), bahwa faktor predisposisi (predisposing factors) yang dapat mempengaruhi suatu perilaku terwujud dalam pengetahuan, sikap, kepercayaan, sumber informasi, keyakinan, nilai-nilai, dan lingkungan.

Berdasarkan data dari Provinsi Sumatera Selatan pada tahun 2018 cakupan ibu hamil yang mendapatkan imunisasi TT yaitu TT1 sebanyak 43,98\% dan TT2 sebanyak 41,05\%, dengan cakupan TT terendah di Kabupaten Muratara TT1 sebanyak $27,1 \%$ dan TT2 sebanyak $21,3 \%$, sedangkan cakupan tertingi di Kota Lubuk Linggau sebanyak TT1 sebanyak 100\% dan TT2 sebanyak 98,6\%. Pada tahun 2018 terdapat $8(19 \%)$ kasus infeksi tetanus dari 42 kasus infeksi mengalami peningkatan pada tahun 2019 menjadi 6 (24\%) kasus infeksi tetanus dari 24 kasus infeksi (Dinkes Provinsi Sumatera Selatan, 2019).

Berdasarkan data dari Dinas Kesehatan
Kabupaten Musi Rawas Utara pada Desember Tahun 2019 dengan jumlah cakupan Imunisasi TT tertinggi pada ibu hamil di Puskesmas Pauh yaitu TT2+ sebanyak $135,2 \%$ dan cakupan Imunisasi $\mathrm{TT}^{+}$terendah di Puskesmas Karang Dapo yaitu TT2 $^{+}$sebanyak $70,41 \%$ dengan cakupan TT1 sebanyak 55,38\% dan TT2 sebanyak 39,17\% (Dinkes Kabupaten Musi Rawas Utara, 2019)

Berdasarkan survey awal pada tanggal 05 Januari 2020 yang dilakukan di Puskesmas Karang Dapo dari 7 orang responden ada 2 orang ibu hamil yang mendengar imunisasi TT dari penyuluhan, 1 orang medengar imunisasi TT dari media sosial dan 4 orang belum mengetahui apa itu imunisasi TT pada ibu hamil. Hal ini disebabkan karena ketidaktahuan ibu tentang imunisasi TT, sumber informasi tentang imunisasi TT yang kurang sehingga ibu hamil banyak yang tidak melakukan imunisasi TT.

Adapun tujuan dari penelitian ini adalah untuk mengetahui hubungan sumber informasi dengan pemberian imunisasi TT pada Ibu Hamil Trimester III di Wilayah Kerja Puskesmas Karang Dapo Kabupaten Musi Rawas Utara.

\section{METODE}

Penelitian ini telah dilakukan pada tanggal 03 - 17 Juli 2020. Penelitian ini mengunakan metode survey analitik, dengan pendekatan secara cross sectional yang bertujuan untuk mengetahui hubungan sumber informasi dengan pemberian imunisasi TT pada Ibu Hamil multipara Trimester III di Wilayah Kerja Puskesmas Karang Dapo Kabupaten Musi Rawas Utara.

Populasi dalam penelitian adalah keseluruhan ibu hamil multipara TM III Di Puskesmas Karang Dapo Kabupaten Musi Rawas Utara sebanyak 31 orang. Sampel dalam penelitian ini diambil menggunakan teknik total sampling yaitu pengambilan sampel secara keseluruhan dari populasi. Jenis pengumpulan data dalam penelitian 
ini menggunakan data primer yaitu dengan cara membagikan kuisioner kepada responden. Analisis data menggunakan analisis univariat dan bivariat dengan uji statistik uji chi square.

\section{HASIL}

\section{Analisis Univariat}

Analisis Univariat dibuthkan untuk mengetahui gambaran dari masing-masing variabel, baik variabel bebas mauoun variabel terikat dengan menggunakan presentase. Hasil analisisnya adalah sebagai berikut.

Tabel 1. Gambaran pemberian imunisasi TT pada ibu hamil di Wilayah Kerja Puskesmas Karang Dapo Kabupaten Musi Rawas Utara

\begin{tabular}{llll}
\hline $\begin{array}{l}\text { N } \\
\text { o }\end{array}$ & $\begin{array}{l}\text { Pemberian } \\
\text { Imunisasi TT }\end{array}$ & $\begin{array}{l}\text { Frekuensi } \\
(\mathbf{f})\end{array}$ & $\begin{array}{l}\text { Persenta } \\
\text { se } \\
(\boldsymbol{\%})\end{array}$ \\
\hline 1 & Tidak Sesuai & 15 & 48.4 \\
2 & Sesuai & 16 & 51.6 \\
\hline & Total & $\mathbf{3 1}$ & $\mathbf{1 0 0}$ \\
\hline
\end{tabular}

Berdasarkan tabel 1 dapat diketahui bahwa pemberian imunisasi TT dari 31 responden terdapat 15 responden tidak melakukan imunisasi TT sesuai jadwal (setiap umur kehamilan di TM II) dan 16

\section{Analisis Bivariat}

Analisis bivariat dilakukan untuk melihat hubungan antara variabel independen (sumber Informasi) terhadap variabel independet ( Pemberian imunisasi TT). Dalam penelitian ini menggunakan analisis bivariate menggunakan uji $\mathrm{Chi}$ Square $\left(x^{2}\right)$. Hasil analisisnya adalah sebagai berikut :

Berdasarkan tabel 3 terlihat bahwa dari 14 responden tidak mendapatkan informasi terdapat 12 responden imunisasi TT tidak sesuai jadwal dan 2 responden sesuai jadwal, dari 17 responden mendapatkan informasi terdapat 3 responden imunisasi TT tidak sesuai jadwal dan 14 responden imunisasi TT responden melakukan imunisasi TT sesuai jadwal (setiap umur kehamilan di TM II ) di Wilayah Kerja Puskesmas Karang Dapo Kabupaten Musi Rawas Utara.

Tabel 2. Gambaran sumber informasi ibu hamil di Wilayah Kerja Puskesmas Karang Dapo Kabupaten Musi Rawas Utara

\begin{tabular}{|c|c|c|c|}
\hline No & $\begin{array}{l}\text { Sumber } \\
\text { Informasi }\end{array}$ & $\begin{array}{l}\text { Frekuensi } \\
\text { (f) }\end{array}$ & $\begin{array}{l}\text { Persent } \\
\text { ase } \\
(\%)\end{array}$ \\
\hline 1 & $\begin{array}{l}\text { Tidak } \\
\text { Mendapatkan }\end{array}$ & 14 & 45.2 \\
\hline 2 & Mendapatkan & 17 & 54.8 \\
\hline & Total & 31 & 100 \\
\hline
\end{tabular}

Berdasarkan tabel 2 diketahui sumber informasi ibu dari 31 responden terdapat 14 tidak mendapatkan informasi (Media cetak, elektronik, internet, petugas kesehatan dan pengalaman terdahulu (bidan/perawat), sumber lain (teman, keluarga, tetangga) dan pengalaman terdahulu) dan 17 responden mendapatkan informasin (Media cetak, elektronik, internet, petugas kesehatan dan pengalaman terdahulu (bidan/perawat), sumber lain (teman, keluarga, tetangga) dan pengalaman terdahulu) di Wilayah Kerja Puskesmas Karang Dapo Kabupaten Musi Rawas Utara.

sesuai jadwal di Wilayah Kerja Puskesmas Karang Dapo Kabupaten Musi Rawas Utara.

Dari hasil uji chi-square dengan dilakukan uji continuity correction nilai $p$ $=0,001<\alpha=0,05$. Hal ini menunjukan bahwa ada hubungan antara sumber informasi dengan pemberian imunisasi TT pada ibu hamil di Wilayah Kerja Puskesmas Karang Dapo Kabupaten Musi Rawas Utara. Hasil uji contingency coefficient didapat nilai $\mathrm{C}=0,561$ dengan $\mathrm{P}=0,000>0,05$. Nilai tersebut dibandingkan yaitu $\frac{\mathbf{C}}{\mathbf{C m a x}}=\frac{\mathbf{0 , 5 6 1}}{\mathbf{0 , 7 0 7}}=0,793$, nilai ini terletak dalam interval 0,60-0,799 maka kategori hubungan kuat 
Tabel 3. Hubungan sumber informasi dengan pemberian imunisasi TT pada ibu hamil di Wilayah Kerja Puskesmas Karang Dapo Kabupaten Musi Rawas Utara

\begin{tabular}{|c|c|c|c|c|c|c|c|c|c|}
\hline \multirow{3}{*}{$\begin{array}{l}\text { Sumber } \\
\text { Informasi }\end{array}$} & \multicolumn{6}{|c|}{ Kesesuai jadwalan Imunisasi } & \multirow{3}{*}{$\chi^{2}$} & \multirow{3}{*}{$\boldsymbol{P}$} & \multirow{3}{*}{$C$} \\
\hline & \multicolumn{2}{|c|}{$\begin{array}{c}\text { Tidak Sesuai } \\
\text { Jadwal }\end{array}$} & \multicolumn{2}{|c|}{ Sesuai Jadwal } & \multicolumn{2}{|c|}{ Total } & & & \\
\hline & $\mathrm{F}$ & $\%$ & $\mathrm{~F}$ & $\%$ & $F$ & $\%$ & & & \\
\hline $\begin{array}{l}\text { Tidak } \\
\text { Mendapatkan }\end{array}$ & 12 & 85,7 & 2 & 14,3 & 14 & 100,0 & \multirow{3}{*}{11.648} & \multirow{3}{*}{$\begin{array}{c}0,00 \\
1\end{array}$} & \multirow{3}{*}{0,561} \\
\hline Mendapatkan & 3 & 17,6 & 14 & 82,4 & 17 & 100,0 & & & \\
\hline Total & 15 & 48,4 & 16 & 51,6 & 31 & 100,0 & & & \\
\hline
\end{tabular}

\section{PEMBAHASAN}

Berdasarkan hasil penelitian diketahui bahwa dari 31 orang responden terdapat 15 responden tidak sesuai jadwal dan 16 responden sesuai dengan jadwal imunisasi. Banyak sekali penyebab tidak sesuainya ibu hamil melakukan imunisasi TT sesuai dengan jadwal yaitu jarak dari rumah ke tempat pelayanan kesehatan, waktu penyuntikan TT, ada beberapa responden yang takut akan jarum suntik, kesibukan responden dll. Sejalan dengan penelitian Ayuningrum dan Murdiati (2017) menyebutkan bahwa hasil penelitian menunjukkan dari 32 responden sebagian besar responden memiliki informasi yang banyak mengenai imunisasi sebanyak 17 orang dengan status imunisasi TT lengkap. Kelengkapan imunisasi TT pada ibu hamil juga dipengaruhi oleh usia ibu hamil dan dukungan dari suami ibu hamil.

Berdasarkan hasil penelitian diketahui dari 31 responden terdapat 14 tidak mendapatkan informasi dan 17 responden mendapatkan informasi dari internet, orang tua, petugas kesehatan, televisi, tetangga di Wilayah Kerja Puskesmas Karang Dapo Kabupaten Musi Rawas Utara.Informasi sangat berpengaruh terhadap tingkat pengetahuan seseorang, informasi dapat diperoleh dari televisi, radio, koran, buku, majalah dan internet, untuk memperoleh informasi dapat membantu mempercepat seseorang untuk memperoleh pengetahuan yang baru. Tidak adanya hubungan antara sumber informasi dengan status imunisasi TT mungkin berhubungan dengan program pemerintah Indonesia yang mewajibkan setiap calon pengantin untuk mendapatkan imunisasi TT sebelum menikah (Emilda, 2018).

Sejalan dengan peneltian yang dlakukan oleh Munawaroh (2016) menyebutkan bahwa dari hasil uji statistik didapatkan bahwa ada hubungan antara media informasi dengan imunisasi tetanus toksoid dua pada ibu hamil trimester tiga. Media informasi adalah hal yang sangat dibutuhkan oleh setiap individu, karena semakin banyak media informasi yang diperoleh baik dari media cetak ataupun dari media elektronik maka akan semakin luas dan banyak pengetahuannya, sehingga usaha sadar tentang pentingnya menjaga kesehatan akan semakin tinggi. Dengan banyaknya media informasi yang diperoleh ibu hamil tentang pentingnya melakukan imunisasi tetnus toksoid, maka minat ibu hamil untuk melakukan imunisasi tetnus toksoid akan semakin meningkat akan tetapi apabila ibu hamil tidak mendapatkan.

Dari hasil uji chi-square dengan dilakukan uji continuity correction nilai $p$ $=0,001<\alpha=0,05$. Hal ini menunjukan bahwa ada hubungan antara sumber informasi dengan pemberian imunisasi TT pada ibu hamil di Wilayah Kerja Puskesmas Karang Dapo Kabupaten Musi Rawas Utara, dengan kategori hubungan kuat, artinya faktor sumber informasi 
merupakan faktor dominan yang berhubungan dengan kelengkapan imunisasi TT pada ibu hamil TM III, akan tetapi masih terdapat faktor lain seperti, usia, pekerjaan, pendidikan dan paritas.

Sejalan dengan penelitian yang dilakukan oleh Ervina (2019) yang menyebutkan bahwa ada hubungan sumber informasi dengan Kelengkapan Imunisasi Tetanus Toksoid pada Ibu Hamil Di Wilayah Kerja Puskesmas Batoh Kota Banda Aceh, yaitu pada ibu hamil yang tidak mendapatkan informasi mengenai pentingnya imunisasi TT tidak lengkap mendapatkan imunisasi TT.

Penyebab lain rendahnya cakupan imunisasi TT menurut penelitian Syarifah (2016) menjelaskan bahwa faktor yang berkaitan dengan pengetahuan terdiri dari kurang terpapahnya informasi. Kurang daya ingat/hafalan, salah menafsirkan informasi keterbatasan kongnitif, kurang berminat dan tidak familiar terhadap sumber daya informasi. Informasi adalah suatu keterangan, penerangan atau data yang telah diproses kedalam suatu bentuk yang mempunyai arti bagi si penerima dan mempunyai nilai yang nyata, sehingga dapat meningkatkan pengetahuan yang dapat dipakai sebagai dasar untuk mengambil keputusan untuk masa yang akan dating.

Berdasarkan hasil uraian diatas dapat diketahui bahwa sumber informasi sangat berpengaruh dalam pemberian imunisasi TT pada ibu hamil. Sumber informasi adalah hal yang sangat dibutuhkan oleh setiap individu, karena semakin banyak sumber informasi yang diperoleh baik dari media cetak maupun dari media elektronik maka akan semakin luas dan banyak pengetahuannya sehingga sadar tentang pentingnya melakukan imunisasi TT, akan tetapi apabila ibu tidak mendapatkan media informasi tentang imunisasi TT maka ibu tidak akan melakukan imunisasi TT. Diharapkan agar tenaga kesehatan agar bisa melakukan penyuluhan, membuah leafet dan memberikan informasi tentang Imunisasi TT agar cakupan imunisasi TT bisa tercapat

\section{KESIMPULAN}

Ada hubungan antara sumber informasi dengan pemberian imunisasi TT pada ibu hamil di Wilayah Kerja Puskesmas Karang Dapo Kabupaten Musi Rawas Utara, dengan kategori hubungan kuat, artinya faktor sumber informasi merupakan faktor dominan yang berhubungan dengan kelengkapan imunisasi TT pada ibu hamil TM III, akan tetapi masih terdapat faktor lain seperti, usia, pekerjaan, pendidikan dan paritas.

\section{UCAPAN TERIMA KASIH}

Terima kasih kepada lokasi penelitian, responden yang telah bersedia membantu, STIKES Tri Mandiri Sakti Bengkulu, Para penulis dan pihak pihak lain yang telah bersedia membantu dalam proses penelitian ini sehingga penelitian ini bisa selesai dengan baik

\section{DAFTAR PUSTAKA}

Indarto, K. (2019). Prevelansi Tetanus Neonatorum DI Dunia. Data Statistik

Kemenkes RI. (2020). Capaian Cakupan Imunisasi Tahun 2020. Kemenkes RI

Maryunani, A. (2016). Manajemen Kebidanan Terlengkap. Jakarta Timur: CV. Trans Info Media

Emilda. (2018). Hubungan Sumber Informasi dengan kelengkapan Imunisasi Tetanus Texoid pada Ibu Hamil Di Wilayah Kerja Puskesmas Batoh Kota Banda Aceh.diunduh dari http://repository.helvetia.ac.id/1266/1/ COVER. pdf. diakses pada tanggal 17 Januari 2020. Vol 01 Nomor 3

Munawaroh. (2016). Faktor-Faktor Yang Berhubungan Imunisasi TT pada Ibu Hamil. Diunduh dari http://journal.unas.ac.id/ilmu- 
budaya/article/download/414/313. (diakses tanggal 12 Januari 2020)

Dinas Kesehatan Provinsi Sumatera Selatan. (2019). Profil Dinas Sumatera Selatan Bengkulu 2018. Provinsi Sumatera Selatan

Dinkes Kabupaten Musi Rawas Utara. 2019. Profil Dinas Kesehatan Musi Rawas Utara Tahun 2019. Kabupaten Musi Rawas utara.

Ayuningrum dan Murdiyati. (2019). Hubungan Tingkat Pengetahuan Tentang Imunisasi Tetanus Toksoid Dengan Kelengkapan Imunisasi Tetanus Toksoid Pada Ibu Hamil Primigravida Di Puskesmas Rowosari Kota Semarang. Diunduh dari http://jurnal.abdihusada.ac.id/index.ph p /jurabdi/article/view/38. diakses tanggal (11 Januari 2020).Vol 04 Nomor 01 Halaman 1007-1012

Ervina. (2019). Hubungan antara pengetahuan dan sumber informasi dengan kelengkapan pemberian imunisasi TT pada ibu hamil di Wilayah Kerja Puskesmas Kabupaten Musi Rawas Utara. Skripsi TMS Bengkulu.

Syarifah. (2016). Hubungan Sumber Informasi dengan kelengkapan Imunisasi Tetanus Texoid pada Ibu Hamil Di Puskesmas Mandai Kelurahan Bontoa Kecamatan Mandai Kabupaten Maros.diunduh dari

http://repository.helvetia.ac.id/1266/1/ COVER. pdf. diakses pada tanggal 17 Januari 2020 